\title{
MAHATMA GANDHI DAN PERANANNYA DALAM MEWUJUDKAN KEMERDEKAAN INDIA
}

\author{
Umi Hartati \\ Program Studi Pendidikan Sejarah, FKIP Universitas Muhammadiyah Metro \\ Email: hartatiumi18@gmail.com
}

\begin{abstract}
Abstrak
Penelitian ini bertujuan untuk mengetahui peran Mahatma Gandhi dalam usaha mewujudkan kemerdekaan India tahun 1914-1947. Jenis penelitian ini adalah penelitian historis. Teknik pengumpulan data dalam penelitian ini menggunakan langkah-langkah heuristik dan teknik kepustakaan. Keabsahan pengumpulan data menggunakan kritik intern dan ekstern dengan langkah interpretasi dan historiografi. Hasil penelitian ini adalah Mahatma Gandhi mengajak rakyat India untuk melawan Kolonial Inggris dengan cara melawan tanpa kekerasan yang disebut satyagraha dan juga mengajak rakyat India untuk menggunakan produk dalam negeri dalam memenuhi kebutuhan sehari-hari yang disebut swadesi.
\end{abstract}

Kata Kunci : Mahatma Gandhi, Politik, ekonomi, Kemerdekaan India.

\begin{abstract}
This study aims to determine the role of Mahatma Gandhi in the effort to realize India's independence in 1914-1947. This type of research is historical research. Data collection techniques in this study using heuristic steps and literature techniques. The validity of data collection uses internal and external criticism with the steps of interpretation and historiography. The result of this research is Mahatma Gandhi invites the people of India to fight the British Colonial by fighting non-violence called satyagraha and also invite the people of India to use domestic products in fulfilling daily necessities called swadesi.
\end{abstract}

Keywords: Mahatma Gandhi, Politics, Economics, Indian Independence.

\section{PENDAHULUAN}

Kemerdekaan merupakan hak setiap manusia di dunia ini. Dengan kata lain tidak ada satupun manusia atau bangsa yang memiliki hak untuk menjajah manusia maupun bangsa lain. Seperti halnya kemerdekaan yang terjadi di negara India pada tanggal 15 Agustus 1947. Jauh sebelum kemerdekaan itu diraih oleh India tentunya perlu banyak perjuangan. Salah satunya adalah perjuangan untuk melawan penjajah Inggris. Negara Inggris adalah sebuah negara yang berada di kawasan Benua Eropa. Latar belakang dan tujuan mereka datang ke India adalah untuk mencari rempah-rempah dan tujuan perdagangan, tetapi hal itu menjadi berubah setelah Inggris tahu bahwa India banyak memiliki kekayaan alam. Mereka berubah ingin menjajah India dan menguasai India sebagai daerah kekuasaanya.

\section{Ketika pecah Perang Dunia} Pertama pada bulan Agustus tahun 1914, India menunjukkan keiklasan hati yang tak disangka oleh Inggris. Propaganda Inggris kepada orang-orang India tentang perjuangan mereka untuk hak-hak bangsa-bangsa kecil berjuang pada 
kesetiaan dan kepercayaan. Hal itu ditunjukkan dengan para raja-raja mengirim tentara, memberi uang dan perhiasan, penduduk memberi sumbangan berupa uang dan tenaga serta rombongan-rombongan palang merah dibentuk.

Propaganda yang idealis ini hilang beberapa bulan setelah disadari, bahwa sama sekali tidak akan ada pembalasan budi dalam bentuk janji yang dapat memuaskan perasaan tidak senang yang berlangsung berpuluh tahun itu. Orang-orang India masih tidak diperbolehkan menjabat pangkat perwira, dan dilarang untuk mempunyai senjata api selain ketentaraan.

Harian-harian orang Inggris mengajak akan kesanggupan bertempur prajurit India. Seiring dengan berjalannya waktu, maka muncullah tokoh besar di India yang dikenal dengan nama Mahatma Gandhi. Beliau seorang negarawan yang mengobarkan semangat nasionalisme di India, selain itu juga beliau adalah seorang tokoh yang membawa India menuju kemerdekaan.

Mahatma Gandhi menerapkan ke empat ajarannya yaitu ahimsa (melawan tanpa kekerasan), hartal (mogok kerja), satyagraha (tidak mau bekerjasama dengan pihak asing) serta swadeshi (tidak mau memakai produk luar negeri) untuk melawan atau mengusir penjajah Inggris yang telah membuat rakyat India menjadi sengsara. Ketika Gandhi memegang pimpinan di dalam rakyat India, semangat penduduk menyalanyala seperti yang belum pernah tampak padanya.

Pada 1 Maret 1919 Gandhi mengeluarkan suatu manifesto yang isinya bahwa telah diputuskan untuk terus melakukan gerakan satyagraha sampai rencana undang-undang India, maka Gandhi menganjurkan untuk melakukan hartal yaitu suatu hari untuk berpuasa dan merenung. Menurut I Gede Suwantana (2007:17) mengatakan bahwa :

Gandhi adalah seorang yogi
yang terjun dalam politik.
Sebenarnya politik Gandhi tak bisa
dibedakan dari agamanya. la
mengatakan bahwa rasa
patriotismenya adalah mengabdi
kepada agamanya. Dalam politik ia
berpegangan pada pertimbangan
moral dan sebagai Mahatma ia
berpendapat bahwa tempatnya
bukanlah di dalam gua atau kuil,
melaikan ditengah-tengah hiruk
pikuk perjuangan rakyat untuk
hak-haknya dan demi kebenaran.
Agama Gandhi membuat jadi
politis dan politisnya beragama.

Dari kutipan di atas dapat diambil pengertian bahwa Mahadma Gandhi merupakan seorang yang terjun di dalam politik. Meskipun Gandhi terjun didunia politik, ia tidak bisa dipisahkan dengan agamanya. Agama Gandhi membuat dirinya menjadi politis dan pilitisnya beragama.

Sebagai politikus yang berjiwa Mahatma atau Mahatma yang berpolitik, serta segala kemampuan yang 
diperolehnya dari sikap penahanan diri, Gandhi tidaklah mungkin mencapai citacitanya jika tidak mempunyai senjata yang khas. Senjata seperti ini tidak pernah ada sebelumnya dan masih bisa ditiru sampai saat ini. Gandhi menyebut nama dari senjata itu adalah satyagraha. Satya berarti kebenaran, Agraha adalah kekuatan. Jadi satyagraha dapat diterjemahkan menjadi kekuatan jiwa.

Dalam tulisan Gandhi, satyagraha berarti pembelaan terhadap kebenaran dengan tidak membuat musuh menderita tetapi dengan membuat kita sendiri menderita. Musuh mesti dikeluarkan dari kesesatan dengan kesabaran dan hati terbuka. Satyagraha mengandung interaksi yang bijak dan terus-menerus antara kedua pihak dengan harapan bahwa mereka akhirnya akan berdamai. Kekerasan, penghinaan, dan propaganda yang berapi-api merintangi tujuan ini. Selain itu juga Gandhi menggunakan gerakan nonkooperasi, yang artinya tidak mau bekerja sama dengan penjajah Inggris.

Dari permasalahan di atas, maka tujuan dari penelitian ini akan dikaji peran Mahatma Gandhi di bidang politik dan ekonomi dalam mewujudkan kemerdekaan India tahun 1914 -1947.

\section{METODE PENELITIAN}

Jenis penelitian ini adalah penelitian historis. Teknik pengumpulan data dalam penelitian ini menggunakan langkah-langkah heuristik dan teknik kepustakaan. Keabsahan data menggunakan kritik intern dan ekstern. Langkah berikutnya yakni Interpretasi data dan pemaparan/penulisan hasil penelitian (historiografi).

\section{HASIL DAN PEMBAHASAN}

Negara India terletak di kawasan Asia Selatan dengan mayoritas penduduknya beragama Hindu, sisanya minoritas beragama Islam, Budha, Sikh, Jain, Kristen. Seperti halnya di benua Asia, India juga pernah mengalami penjajahan pada masa pendudukan Inggris. Pada awalnya Inggris hanya mencari rempah-rempah di India dan akhirnya berujung dengan memonopoli perdagangan serta menguasai India.

Awal mula aktivitas Inggris di India dalam bidang perdagangan yang dilakukan oleh badan niaga EIC (English East India Company) sejak dibentuk pada 1600 oleh para pedagang London. Badan niaga ini, oleh pemerintah Kerajaan Inggris, diberi hak monopoli perdagangan di wilayah antara Inggris dengan dunia timur yaitu India, Indonesia dan China (Suwarno, 2012:106).

Keberadaan Inggris di India dengan waktu cukup lama dan mempunyai niat untuk menguasainya membuat masyarakat India tertindas dan dipaksa bekerja untuk memenuhi 
kebutuhan Inggris tanpa diberi imbalan apapun. Melihat kejadian tersebut, tergugahlah hati salah seorang politikus dari India yang bernama Mahatma Gandhi yang berusaha untuk melawan Inggris.

Gandhi adalah seorang yogi yang terjun dalam politik. Sebenarnya politik Gandhi tidak bisa dibedakan dari agamanya. la mengatakan bahwa rasa patriotismenya adalah mengabdi kepada agamanya. Dalam politik ia berpegangan pada pertimbangan moral dan sebagai Mahatma ia berpendapat bahwa tempatnya bukanlah di dalam gua atau kuil, melainkan di tengah-tengah hirukpikuk perjuangan rakyat untuk hakhaknya dan demi kebenaran. Agama Gandhi membuat dirinya menjadi berpolitis dan politiknya beragama. Sebagai politikus yang berjiwa Mahatma, atau Mahatma yang berpolitik, serta segala kemampuan yang diperolehnya dari sikap penahanan diri, Gandhi tidaklah mungkin mencapai cita-citanya jika tidak mempunyai senjata yang khas. Senjata seperti ini tidak ada sebelumnya dan masih ditiru sampai saat ini. Gandhi menyebut nama dari senjata itu adalah satyagraha. Satya berarti kebenaran, Agraha adalah kekuatan. Jadi satyagraha dapat diterjemahkan menjadi kekuatan jiwa (I Gede Suwantana, 2007:17).

Keluarga Gandhi merupakan penganut setia paham Waisnawa, sebuah praktek beragama Hindu yang mengutamakan pemujaan terhadap Wisnu dan mengalami proses percampuran dengan Jainisme. Jainisme adalah aliran agama di India yang salah satu ajarannya adalah melarang keras praktek kekerasan dan pembunuhan terhadap segala jenis makhluk hidup. Keluarga Gandhi menganut kasta Bania. Kasta ini merupakan bagian dari kasta Waisya, dan kebanyakan mereka bekerja sebagai petani dan pedagang (Francis Alappatt, 2005:3).

Mahadma Gandhi mengajak masyarakat India untuk dapat melawan Inggris dengan cara politiknya yang disebut satyagraha yaitu tidak mau bekerja sama dengan pihak asing demi terbebas dari siksaan Inggris dan mendapatkan kemerdekaan yang seutuhnya.

India tidak akan mendapat apaapa apabila mereka masih berhubungan dengan pemerintah ataupun orang Inggris. Satyagraha

resmi digunakan sebagai strategi untuk meraih kemerdekaan. Demi lebih mempertegas arah perjuangannya, Gandhi memilih roda pemintal sebagai “lambang pembebasan." la mengajak orang-orang untuk melakukan pekerjaan yang dapat mengurangi kemiskinan dan membangkitkan ekonomi pedesaan (Mehta, 2002).

Untuk pertama kalinya satyagraha dilakukan untuk menolak 
undang-undang yang dibuat oleh Inggris yang menuntut semua orang India di atas umur 8 tahun didaftar dan diambil sidik jarinya dengan resmi untuk tidak masuk Transvaal secara ilegal. Jika tidak melakukan hal tersebut maka akan diberikan denda, dipenjara, dan dikeluarkan dari provinsi.

Gandhi mengajak masyarakat India untuk dapat melawan Inggris dengan cara politiknya yang disebut satyagraha yaitu melawan tanpa kekerasan demi terbebas dari siksaan Inggris dan mendapatkan kemerdekaan yang seutuhnya.

Pada awalnya masyarakat India tidak mau mengikuti ajaran Gandhi tersebut, tetapi setelah diberi penjelasan tentang ajaran satyagraha bahwa melawan Inggris tanpa menggunakan kekerasan bukan berarti tunduk terhadap perintah Inggris, hanya saja yang akan diperangi adalah kejahatan yang dilakukan oleh Inggris, bukan orang Inggris yang diperangi.

Untuk pertama kalinya satyagraha dilakukan untuk menolak undang-undang yang dibuat oleh Inggris yang menuntut semua orang India di atas umur 8 tahun didaftar dan diambil sidik jarinya dengan resmi untuk tidak masuk Transvaal secara ilegal. Jika tidak melakukan hal tersebut maka akan diberikan denda, dipenjara, dan dikeluarkan dari provinsi.
Gandhi memimpin orang-orang India untuk menolak undang-undang tersebut dan akhirnya dipenjara oleh Inggris. Tak lama kemudian utusan Jenderal Smuts mendatangi Gandhi di penjara dengan mengatakan akan dicabutnya undang-undang tersebut jika orang India mau mendaftarkan dirinya secara sukarela. Tawaran tersebut diterima oleh Gandhi dan akhirnya Gandhi dibebaskan dari penjara.

Kantor-kantor Gandhi di Johannesburg menjadi markas besar umum gerakan satyagraha. Di saat lain juga di pertanian Phoeniz Natal. Di pertanian itu mereka hidup secara sederhana. Mereka tidur di bawah langit di atas kain tipis kecuali bila hujan. Mereka menghindari kesenangan materiil dan memusatkan diri pada perlawanan yang akan datang. Gandhi menulis bahwa seorang satyagraha bila mungkin harus lebih berpikiran seimbang, karena ini merupakan latihan perjuangan moral. Persoalan yang dihadapi orang India saat ini adalah memutuskan untuk melawan larangan imigran ke Transvaal terhadap orangorang India dan dengan sengaja berusaha ditangkap. Dalam hal ini Gandhi meniru Thoreau untuk menjalankan ketidakpatuhan sipil. Dalam ketidakpatuhan sipil, Thoreau mengatakan sebagai satu-satunya kewajiban yang berhak diterimanya kapan saja untuk berbuat benar. la 
merasa lebih terhormat untuk berada di pihak yang benar dari pada mentaati hukum (I Gede Suwantana, 2007:19-20).

Selain menjalankan ajaran satyagraha Gandhi juga mengajak orang India untuk melakukan politik nonkooperasi yaitu menolak kerjasama Inggris dengan tidak membeli barangbarang buatan Inggris, tidak sekolah yang didirikan oleh Inggris, tidak membayar pajak Inggris, dan tidak bekerja di pemerintahan Kolonial Inggris. Untuk memenuhi kebutuhan keseharian orang India, Gandhi menyarankan dapat memakai produk dalam negeri atau dapat memenuhi kebutuhan masing-masing dengan membuatnya sendiri tidak bergantung dengan Inggris.

Jawaharlal Nehru mengatakan bahwa dalam perlawanan ini terdapat campuran aneh antara nasionalisme, politik, agama, mistisisme, dan fanatisme. "Sebuah demoralisasi, terbelakang, dan orang-orang patah (semangat) tiba-tiba menegakkan punggung mereka dan mengangkat kepala mereka dan mengambil bagian dalam disiplin, aksi bersama dalam skala seluruh negeri” (Wied Prana, 2010:77).

Dengan politik non-kooperasi tersebut membuat kas negara Inggris semakin berkurang, ditambah lagi dengan orang Inggris yang senang dengan menghambur-hamburkan kekayaannya dan berakibat kas negara mulai kosong kembali.

Pada Agustus 1942, Gandhi memprakarsai program "Quit India” untuk menuntut agar Inggris segera keluar dan meninggalkan India secepatnya serta untuk menggalang massa dalam skala yang luas dengan dasar tanpa kekerasaan. Program ini disahkan oleh BP Kongres pada 8 Agustus 1942 (Suwarno, 2012:132).

selain melakukan satyagraha, Gandhi juga mengajak orang India untuk melakukan pemboikotan semua barangbarang milik Inggris dan untuk menggunakan produk dalam negeri dalam memenuhi kebutuhan sehari-hari.

Untuk memenuhi kebutuhan sehari-hari Gandhi mengajarkan kepada orang India untuk dapat memanfaatkan alam sekitar yang dapat digunakan dalam memenuhi kebutuhan diantaranya pakaian dan makanan. Dalam hal pakaian Gandhi mengajarkan untuk dapat membuat baju sendiri dan ia menciptakan alat yang disebut roda pemintal yang berfungsi untuk menenun kain yang akan diolah menjadi pakaian, sedangkan dalam hal makanan Gandhi mengajarkan kepada orang India untuk dapat menanam berbagai macam tanaman serta mengolahnya sendiri menjadi makanan.

Dalam ajarannya ini Mahatma Gandhi menyebutnya dengan nama swadesi yang artinya memakai produk 
dalam negeri dan memboikot produkproduk luar negeri.

Barang-barang produksi luar negeri ini diboikot bukan semata-mata karena barang-barang itu berasal dari negara asing, tetapi hanya disebabkan karena hingga saat ini keberadaan produk asing itu terbukti membahayakan kepentingan nasional bangsa India. Barang utama yang diboikot adalah pakaian yang diproduksi luar negeri, dan aksi ini masuk dalam sumpah swadeshi yang dilakukan oleh para pejuang dari Kongres dan aktivis-aktivis lainnya.Sumpah ini dilakukan secara sukarela. Sumpah tersebut mengharuskan 'hanya akan menggunakan pakaian tersebut dari kapas, wol atau sutera yang diproduksi di India, baik hasil tenunan maupun pemintalan dengan tangan'. Tetapi boikot hanyalah salah satu aspek yang dibutuhkan oleh rakyat India (Francis Alappatt, 2005:113).

Semua itu Gandhi lakukan untuk dapat mengusir Kolonial Inggris dari India. Dengan mengajak orang India untuk melakukan ajaran swadesinya yaitu menggunakan produk dalam negeri atau memproduksi semua kebutuhan sendiri dan memboikot barang-barang dari luar negeri, maka orang India tidak lagi akan bergantung kepada Inggris dalam memenuhi kebutuhan sehari-hari.

Dengan adanya satyagraha dan swadesi yang dijalankan oleh Mahadma
Gandhi beserta rakyat India, kolonialis Inggris lambat laun mengalami kemerosotan terutama di bidang ekonomi. Rakyat India tadak ada lagi yang bekerja dengan Inggris, tidak mau lagi menggunakan produk-produk luar negeri yang mengakibatkan kas negara mereka semakin lama semakin menurun dan akan berdampak kepada Inggris untuk segera meninggalkan negara India.

\section{PENUTUP}

\section{Simpulan}

Berdasarkan penelitian di atas dapat disimpulkan bahwa:

a. Untuk dapat mencapai kemerdekaan dan terbebas dari Kolonial Inggris, Mahatma Gandhi mengajak orang India untuk melawan Inggris dengan menggunakan senjata yang diberi nama satyagraha yaitu melawan tanpa kekerasan dan swadesi yaitu menggunakan produk dalam negeri.

b. Dengan menggunakan politik nonkooperasi yaitu tidak mau bekerja sama dengan Kolonial Inggris dalam bentuk apapun, mengakibatkan kas negara Inggris semakin berkurang dan membuat orang India semakin mudah dapat mengusir Inggris untuk segera meninggalkan India dan memberikan kemerdekaannya secara utuh. 
c. Dengan manjalankan ajaran Mahadma Gandhi yang disebut swadesi yaitu memakai produk dalam negeri dan memboikot barang-barang luar negeri menjadikan rakyat India tidak bergantung lagi kepada Inggris.

\section{Saran}

Berdasarkan hasil penelitian yang telah dikemukakan di atas, maka dapat diberikan saran antara lain:

a. Dalam menyelesaikan semua masalah hendaknya harus diselesaikan dengan tidak menggunakan kekerasan agar tidak terjadi kerusuhan ataupun pertikaian yang mengakibatkan jatuhnya korban jiwa.

b. Berjuang tanpa kekarasan bukan berarti kita tidak boleh melawan musuh. Hanya saja yang kita musuhi adalah kejahatan yang dilakukan oleh manusia, bukan manusianya.

\section{DAFTAR PUSTAKA}

Fransicis, Alappatt. 2005. Mahatma Gandhi Prinsip Hidup, Pemikiran Politik dan Konsep Ekonomi. Nusamedia Bekerjasama dengan Nuansa: Bandung.
I Gede Suantana. 2007. Mahatma Gandhi. Jakarta: Geneca Press.

Mehta, Ved. 2002. Ajaran-ajaran Mahatma Gandhi: kesaksian dari para pengikut dan musuhmusuhnya. Yogyakarta: Pustaka Pelajar.

Wied, Prana. 2010. Gandhi Manusia Bijak Dari Timur. Jogjakarta :Garasi.

Suwarno. 2012. Dinamika Sejarah Asia Selatan. Yogyakarta : Ombak. 